\title{
KRAS mutation detection and prognostic potential in sporadic colorectal cancer using high-resolution melting analysis
}

\author{
V Deschoolmeester, ${ }^{*, 1,5}$, C Boeckx ${ }^{1,5}$, M Baay ${ }^{1,5}$, J Weyler², W Wuyts ${ }^{3}$, E Van Marck ${ }^{4}$, M Peeters', F Lardon' \\ and JB Vermorken'
}

'Laboratory of Cancer Research and Clinical Oncology, Department of Medical Oncology, University of Antwerp/Antwerp University Hospital, Wilrijk 2610, Belgium, ${ }^{2}$ Department of Epidemiology and Social Medicine, University of Antwerp. Wilrijk 2610, Belgium, ${ }^{3}$ Department of Medical Genetics, University of Antwerp/Antwerp University Hospital, Wilrijk 2610, Belgium; ${ }^{4}$ Department of Pathology, University Hospital of Antwerp, Edegem 2650 , Belgium

\begin{abstract}
BACKGROUND: The development of targeted therapies has created a pressing clinical need for molecular characterisation of cancers. In this retrospective study, high-resolution melting analysis (HRMA) was validated and implemented for screening of I64 colorectal cancer (CRC) patients to detect KRAS hot-spot mutations and to evaluate its prognostic value. Direct sequencing was used to confirm and characterise HRMA results.

METHODS: After establishing its sensitivity, HRMA was validated on seven cell lines and inter- and intra-variation were analysed. The prognostic value of KRAS mutations in CRC was evaluated using survival analysis.

RESULTS: HRMA revealed abnormal melting patterns in 34.1\% CRC samples. Kaplan-Meier survival curves revealed a significantly shorter overall (OS) and disease-free survival (DFS) for CRC patients harbouring a KRAS mutation. In the Cox regression analysis, only when colon and rectal cancer were analysed separately, KRAS mutation was a negative predictor for OS in patients with rectal cancer and DFS in those with stage II colon cancer.

CONCLUSIONS: HRMA was found to be a valid screening method for KRAS mutation detection. The KRAS mutation came forward as a negative predictive factor for OS in patients with rectal cancer and for DFS in stage II colon cancer patients.

British Journal of Cancer (2010) 103, 1627- 1636. doi:I0.1038/sj.bjc.6605959 www.bjcancer.com

Published online 19 October 2010

(c) 2010 Cancer Research UK
\end{abstract}

Keywords: colorectal cancer; high-resolution melting analysis; prognosis; KRAS; survival analysis

Among the most daunting challenges facing oncology today is that of patient selection, particularly for therapy with molecularly targeted agents (Jimeno et al, 2009). Hence, robust prognostic markers and markers predictive for treatment response, resistance and toxicity are necessary.

For example, the epidermal growth factor receptor (EGFR) has become an important target for treatment of metastatic colorectal cancer (mCRC), specifically with the monoclonal antibodies (mAbs) cetuximab and panitumumab (Heinemann et al, 2009). Several reports indicate that an increased gene copy number of EGFR or mutations of genes responsible for downstream signalling, especially $K R A S$, are important determinants of response or resistance to anti-EGR antibodies (Heinemann et al, 2009).

KRAS is part of a group of three homologous oncogenes and encodes a small $21 \mathrm{kDa}$ protein (p21Ras) involved in the transduction of external stimuli to effector molecules across plasma membranes, downstream from the EGFR. This protein has intrinsic guanosine triphosphatase (GTPase) activity, allowing inactivation after signal transduction in the normal cellular

\footnotetext{
*Correspondence: Dr V Deschoolmeester;

E-mail: vanessa.deschoolmeester@ua.ac.be

${ }^{5}$ These authors contributed equally to this work.

Revised 26 September 2010; accepted 28 September 2010; published online 19 October 2010
}

environment. Somatic point mutations of KRAS occurring early in CRC tumourigenesis are thought to abolish GTPase activity, leading to a constitutive activation of KRAS, and inevitably to increased and unregulated cellular proliferation and malignant transformation (Adjei, 2001; Conlin et al, 2005). Oncogenic mutations of the KRAS gene are observed in $\sim 40 \%$ of sporadic CRC, and up to $90 \%$ of these mutations are detected in codons 12 and 13 and less frequently also in codons 61 and 63 (Heinemann et al, 2009). The functions of KRAS support its putative predictive and prognostic role in CRC, and several studies have been performed trying to illustrate this (Graziano and Cascinu, 2003).

With respect to its predictive role, several retrospective analyses of tumour samples in CRC patients receiving anti-EGFR antibody treatment have shown that patients with mutated KRAS did not benefit from anti-EGFR therapy (Lievre et al, 2006; Amado et al, 2008). Based on systematic reviews of the relevant literature, the American Society of Clinical Oncology suggested, in a Provisional Clinical Opinion in 2009, that when KRAS mutations in codon 12 or 13 were detected in patients with $\mathrm{MCRC}$, such patients should not receive anti-EGFR antibody therapy as part of their treatment (Allegra et al, 2009). The European Medicines Agency has also recognised these findings, and indeed also restricts the use of antiEGFR antibody therapy only to CRC patients with wild-type (wt) KRAS tumours (Javle and Hsueh, 2009).

With respect to its prognostic role in CRC, literature data on the impact of KRAS mutations on outcome has been controversial, 
including in those with node-negative disease, for whom a discriminator would be most useful (Jimeno et al, 2009, and as reviewed by Anwar et al, 2004; Klump et al, 2004; Locker et al, 2006).

In addition, with the advent of personalised medicine, there is a compelling need for rapid and accurate methods for detection of nucleic acid sequencing changes, such as, KRAS mutations, in clinical specimen (Krypuy et al, 2006). A wide range of mutation detection techniques exists, of which sequencing has been the gold standard (Krypuy et al, 2006). However, its limited sensitivity, high costs and long turnaround time have prompted the development of alternative methods for routine clinical testing that have greater diagnostic practicality for somatic mutation detection (Do et al, 2008). High-resolution melting analysis (HRMA) is a recently developed methodology that has enormous potential for the detection of DNA sequence changes (Do et al, 2008). Mutation scanning with HRMA is based on the dissociation behaviour of DNA when exposed to an increasing temperature, in the presence of intercalating fluorescent dyes. The HRMA melting profile gives a sequence-related pattern, allowing discrimination between wt sequences and homozygote-heterozygote variants (Giuliani et al, 2008). Owing to its high sensitivity, HRMA seems to present a more sensitive approach, allowing rapid, accurate and reliable detection of a minimal fraction of mutated cells in tumoral tissue (Giuliani et al, 2008; Kramer et al, 2009).

The aim of this study was to validate and implement HRMA to detect KRAS mutations in formalin-fixed paraffin-embedded (FFPE) CRC samples. In addition, the prognostic value of KRAS mutation was evaluated in a population of CRC patients.

\section{MATERIALS AND METHODS}

\section{Samples and DNA extraction}

Tissue samples were obtained from 164 sporadic CRC patients treated at the Antwerp University Hospital in Edegem and the St Augustinus Hospital in Wilrijk. DNA was extracted from FFPE tissue blocks as described previously (Deschoolmeester et al, 2006). DNA concentration and purity was defined using the Nanodrop 1000 (Isogen, Sint-Pieters-Leeuw, Belgium). Microsatellite instability (MSI) status was defined previously (Deschoolmeester et al, 2008).

\section{Assay design and PCR conditions}

Primers were designed to span codons 12 and 13 of the KRAS gene. Primers for the 114-bp amplicon of exon 2 were $5^{\prime}$-GCCTGCTG AAAATGACTGAA-3' (forward) and $5^{\prime}$-TTGGATCATATTCGTCC ACAA- $3^{\prime}$ (reverse). The reaction mixture was made up using $2.5 \times$ LightScanner Mastermix (Idoha Technology Inc., Salt Lake City, UT, USA), $1.65 \mathrm{~mm} \mathrm{MgCl}_{2}, 5 \mu \mathrm{M}$ of each sense and antisense primer, $4 \%$ (v/v) DMSO, $2 \mu \mathrm{l}$ genomic DNA or 20 ng cell line DNA and water in a total volume of $10 \mu \mathrm{l}$.

The PCR cycling was performed on the Rapid Cycler Instrument 2 (Idoha Technology Inc.), whereas HRMA was performed on the HR/1 High-Resolution Melter (Idoha Technology Inc.) and measured by the HR/1 Instrument Control software. The 114-bp amplicon was run according to the following conditions: one cycle of $95^{\circ} \mathrm{C}$ for $30 \mathrm{~s}$ and 45 cycles in the following sequence: $95^{\circ} \mathrm{C}$ for $10 \mathrm{~s}, 65^{\circ} \mathrm{C}$ for $10 \mathrm{~s}$ and $74^{\circ} \mathrm{C}$ for $2 \mathrm{~s}$. The results were analysed using the HR/1 Melt Analysis Tool software (Idoha Technology Inc.).

\section{HRMA sensitivity testing}

High-resolution melting analysis sensitivity testing was conducted by mixing a series of dilutions of 50,25, 12.5, 6 and $3 \%$ of mutant KRAS DNA from A549 (G12S, homozygous mutation in codon 12) within wt KRAS DNA from CAL27. In addition, these cell lines were also used as positive and negative controls.

Subsequently, the HRMA of KRAS mutations was validated in a set of DNA obtained from several cell lines (Table 1) with or without a known KRAS mutation.

\section{DNA sequencing}

After HRMA, the PCR products with a deviating pattern were separated on a $2 \%$ low melting point agarose gel (Ultra Pure, Gibco $\mathrm{BRL}$, Merelbeke, Belgium) during $60 \mathrm{~min}$ on $50 \mathrm{~V}$. After separation, the desired bands were excised from the gel and the DNA was isolated and purified using spin procedure for agarose gels (GenElute Gel Extraction Kit, Sigma, Bornem, Belgium). The purified PCR product was then used as template in cycle sequencing using the Big Dye Terminator v1.1 kit (Applied Biosystems, Foster City, CA, USA). The reaction mixture consisted of $1.1 \times$ sequencing buffer, $0.2 \mu \mathrm{l}$ Big Dye mix, $625 \mathrm{~nm}$ primer and $1 \mu \mathrm{l}$ of cleaned template in a total volume of $4 \mu \mathrm{l}$. The forward and reverse reactions were run on a Rapid Cycler Instrument 2 (Idoha Technology Inc.) according to the following protocol: one cycle of $95^{\circ} \mathrm{C}$ for $30 \mathrm{~s}$ and 25 cycles in the following sequence: $96^{\circ} \mathrm{C}$ for $10 \mathrm{~s}$, $50^{\circ} \mathrm{C}$ for $5 \mathrm{~s}$ and $60^{\circ} \mathrm{C}$ for $2 \mathrm{~min}$. The sequencing reactions were run on a 3130 XL Genetic Analyzer (Applied Biosystems). Sequencing data was analysed using SeqScanner software v1.0 (Applied Biosystems).

\section{Statistical analysis}

Prognostic relevance of KRAS mutation was assessed by survival analysis. The index date for survival time calculation was defined as the date of diagnostic confirmation for CRC. The months of observation (overall survival (OS) time) were calculated from the index date to the date of last information/death. For disease-free

Table I Characteristics of the human cell lines used for sensitivity testing and validation of the HRM analysis technique for KRAS mutation detection

\begin{tabular}{llll}
\hline Cell line & Origin (human) & Mutation & Reference \\
\hline A549 & Lung carcinoma & KRAS exon 2: GI2S homozygous & Krypuy et al, 2006 \\
CAL27 & Head and neck carcinoma & & \\
ECV304 & Bladder carcinoma & & \\
SQD9 & Head and neck squamous & & \\
NCI-H292 & carcinoma & KRAS exon 2: GI3D heterozygous & Krypuy et al, 2006; Simi et al, 2008 \\
HCTII6 & Colon carcinoma & KRAS exon 2: GI3D heterozygous & Cosmic data set, Welcome Trust Sanger Institute, \\
MDA-MB231 & Breast carcinoma & & 2009: http://www.sanger.ac.uk/perl/genetics /CPG/ \\
& & & core_line_viewer?action= sample\&id =909960 \\
\hline
\end{tabular}

Abbreviation: HRM= high-resolution melting. 
survival (DFS) time, the months of observation were calculated from the index date to the first date of progression or the date of last information. Survival curves were determined by using the Kaplan-Meier method and were analysed by using the log-rank test.

Possible associations between KRAS mutation and clinicopathological parameters of CRCs were investigated using the $\chi^{2}$-test or Fisher's exact test (when appropriate) for categorical variables and using Student $t$-test or Mann-Whitney $U$-test (when appropriate) for continuous variables. To assess the independent prognostic contribution of KRAS mutation, a multiple Cox regression analysis was conducted. In addition, a stepwise backward binary logistic regression was performed to identify which of the clinicopathological parameters had the strongest impact on survival in CRC. All analyses were conducted using SPSS (version 16.0, SPSS Inc., Brussels, Belgium). Significance for all statistics was recorded if $P<0.05$ (two tailed).

\section{RESULTS}

\section{Patient characteristics}

Of the 164 CRC patients from whom tumour tissue could be obtained, most (but not all) clinical data were retrieved. Most tumours were located in the distal part of the large bowel (68.3\%), and most patients had a stage II or III disease. Further details on these patients are summarised in Table 2 .

\section{Assay sensitivity testing}

Sensitivity of the melting profile in discriminating different percentages of mutated alleles was initially evaluated by using serial dilutions of mutated DNA, derived from a cultured cell line with a known KRAS mutation, variably mixed with wt DNA obtained from a wt cell line. A549 DNA (G12S, homozygous mutation in codon 12) was mixed with wt CAL27 DNA in proportions of $50,25,12.5,6$ and $3 \%$. The difference plot (Figure 1A) shows that HRMA was able to identify the presence of an abnormal profile in all dilutions, allowing the clear identification of mutated alleles. In addition, dideoxy sequencing analysis was performed on the 12.5, 6 and $3 \%$ dilutions using the same PCR product after melting analysis (Figure 1B). The results of HRMA were only confirmed for the $12.5 \%$ dilution by sequencing analysis in both the forward and the reverse primer set. In the case of $6 \%$ (for forward primer) and 3\% (both forward and reverse primer) mutant DNA in wt DNA, sequencing analysis was not able to incontestably confirm the presence of mutant alleles, as seen by the nucleotide sequence generated by the sequencing software.

\section{Assay validation}

Cancer cell lines with or without a known KRAS mutation (Table 1) were first used to test the HRMA methodology. The HRMA was able to discriminate between the wt DNA and the different mutations present in the mutant cell line DNA. As seen in the melting (Figure 2A) and derivative plot (Figure 2B), HCT116, MDA-MB-231 and NCI-H292 showed typical heteroduplex melting patterns and were readily distinguishable from the wt cell lines CAL27 and ECV304. The lung cancer cell line A549 has a homozygous mutation (Table 1) and, as expected, it showed a similar shape to the wt pattern but with earlier melting of the amplified product, which is consistent with the lower thermal stability of AT base pairs relative to GC base pairs. Furthermore, dideoxy sequencing analysis confirmed the HRMA results in all cases (data not shown). In addition, an inter- and intra-variation analysis was performed on three different days in four different cell lines (A549, CAL27, ECV304 and SQD9). The results showed that
Table 2 Clinical characteristics of patients analysed for the overall population and for patients with colon cancer and rectal cancer separately

\begin{tabular}{|c|c|c|c|}
\hline & Colon & Rectum & $\begin{array}{c}\text { Overall } \\
\text { population }\end{array}$ \\
\hline \multicolumn{4}{|l|}{ Patient characteristics } \\
\hline Total no. of patients & 103 & 50 & 164 \\
\hline Median age (years) & $66 \pm 13$ & $63 \pm 12$ & $65 \pm 13$ \\
\hline \multicolumn{4}{|l|}{ Sex } \\
\hline Male & $51(49.5 \%)$ & $24(48.0 \%)$ & $80(48.2 \%)$ \\
\hline Female & $51(49.5 \%)$ & $26(52.0 \%)$ & $78(48.8 \%)$ \\
\hline \multicolumn{4}{|l|}{ Location } \\
\hline Proximal & - & - & 45 (27.4\%) \\
\hline Distal & - & - & $112(68.3 \%)$ \\
\hline \multicolumn{4}{|l|}{ Grade of differentiation } \\
\hline Poor & $10(9.7 \%)$ & $3(6.0 \%)$ & $14(8.5 \%)$ \\
\hline Moderate & $34(33.0 \%)$ & $18(36.0 \%)$ & $55(33.5 \%)$ \\
\hline Well & $56(54.4 \%)$ & $28(56.0 \%)$ & $87(53.0 \%)$ \\
\hline \multicolumn{4}{|l|}{ Stage } \\
\hline i & II (I0.7\%) & $8(16 \%)$ & $20(12.2 \%)$ \\
\hline$\|$ & $43(41.7 \%)$ & $20(40.0 \%)$ & $69(42.1 \%)$ \\
\hline III & $31(30.1 \%)$ & 14 (28.0\%) & $45(27.4 \%)$ \\
\hline IV & $14(13.6 \%)$ & $8(16.0 \%)$ & $22(13.4 \%)$ \\
\hline \multicolumn{4}{|l|}{ Therapy } \\
\hline \multicolumn{4}{|l|}{ Neo-adjuvant } \\
\hline Yes & | (1.0\%) & 19 (38.0\%) & $22(13.4 \%)$ \\
\hline No & $89(86.4 \%)$ & $24(48.0 \%)$ & $120(73.2 \%)$ \\
\hline \multicolumn{4}{|l|}{ Adjuvant } \\
\hline Yes & 35 (34.0\%) & $16(32.0 \%)$ & $57(34.8 \%)$ \\
\hline No & $63(60.2 \%)$ & $27(54.0 \%)$ & $92(56.1 \%)$ \\
\hline \multicolumn{4}{|l|}{ MSI status } \\
\hline MSI & $13(12.6 \%)$ & $0(0.0 \%)$ & $14(8.5 \%)$ \\
\hline MSS & $90(87.4 \%)$ & $50(100 \%)$ & $150(91.5 \%)$ \\
\hline
\end{tabular}

Abbreviations: $\mathrm{MSI}=$ microsatellite instability; $\mathrm{MSS}=$ microsatellite stability. In | | patients the actual location of the tumour was not specified; not all clinical characteristics were available for each patient.

inter- and intra-variation was present and could hamper the interpretation of the results (Figure 3). However, within one experiment, it was still possible to discriminate between DNA of the mutant cell line and that of the three wt cell lines (Figure 4). These results indicate that it is necessary to include positive (mutant) and negative (wt) controls in each experiment. In addition, owing to the inter-variation, it is inadvisable to compare plots generated on different days.

\section{KRAS mutation detection in CRC samples}

The 114-bp amplicon was used to screen for KRAS mutation in codons 12 and 13 of 164 sporadic CRC samples. Aberrant curves were detected in 56 of 164 (34.1\%) samples assayed. A total of 49 samples were confirmed by sequencing analysis and additionally revealed the actual mutation. Seven samples could not be confirmed by sequencing analysis, either due to lack of material or due to inconclusive results. As not all HRMA-positive samples could be confirmed by sequencing, the percentage of established $K R A S$ mutations in CRC is reduced to $29.9 \%$. As shown in Figure 5, $23.2 \%$ of the samples showed mutations in codon 12 , whereas only in $6.7 \%$ of the samples, the mutations was found in codon 13 . Among the different mutations, G12D substitution was the most prevalent $(40.8 \%)$, followed by G13D, G12V and G12C. The other mutations were less frequently detected (Figure 5). 

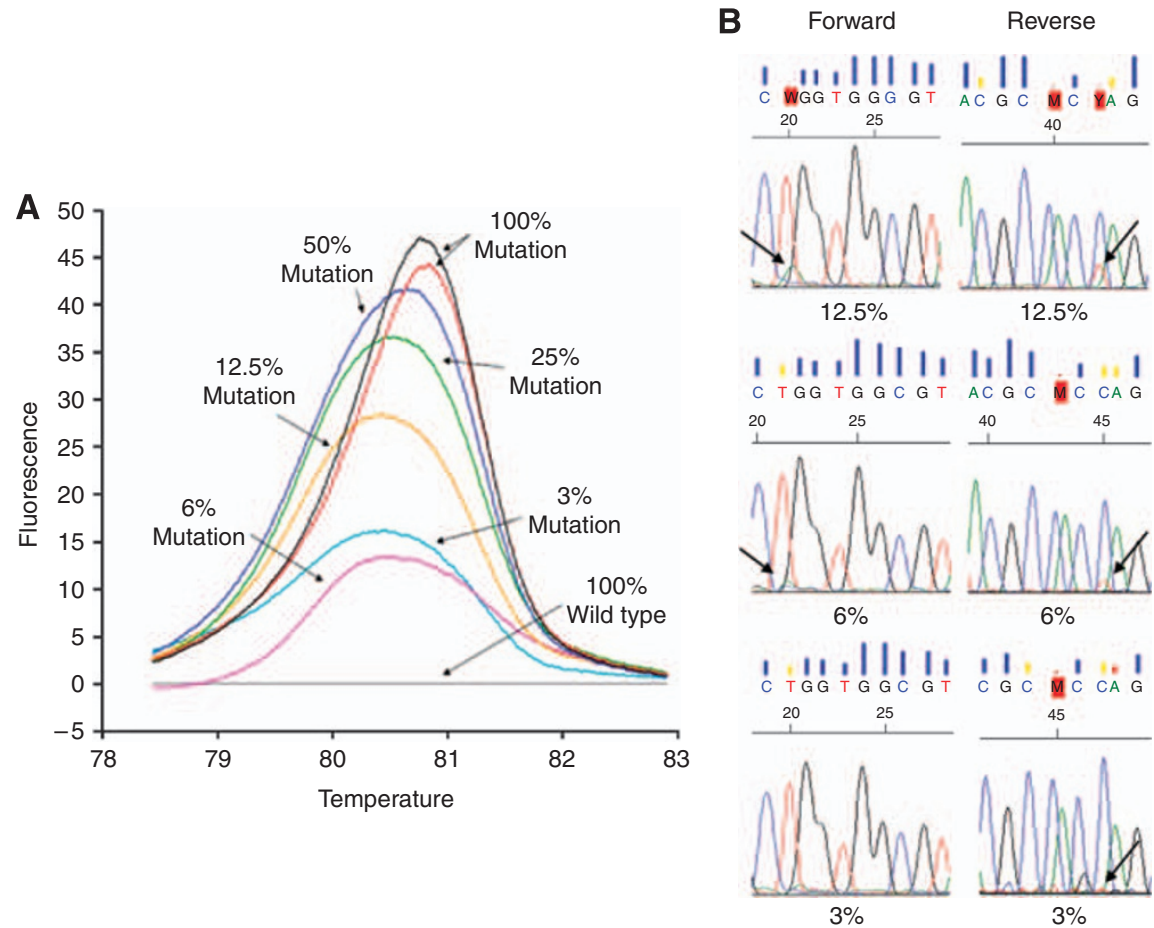

Figure I (A) Difference plot generated with serial dilutions of DNA from a mutated cell line in wild-type DNA to assess HRMA sensitivity. (B) Electropherograms of sequencing analysis for the same serial dilutions. Only $12.5 \%$ could be incontestably confirmed by sequencing analysis.
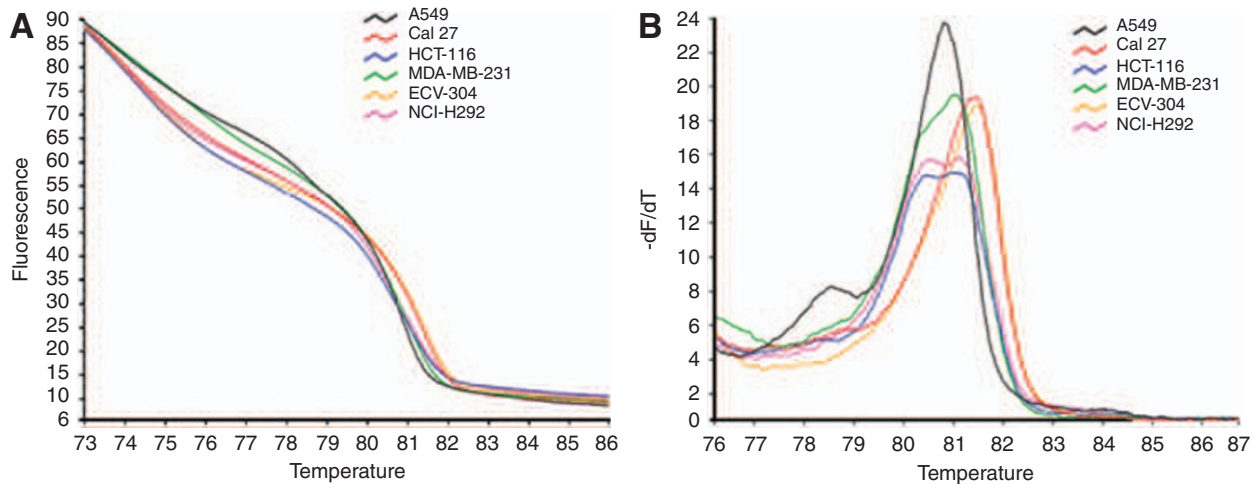

Figure 2 High-resolution melting analysis for different cell lines with or without a known KRAS mutation. (A) Melting curves, not normalised. (B) Derivative plot of the non-normalised melting curves.

\section{Prognostic relevance of KRAS mutation in CRC}

Follow-up for OS and DFS was available for 153 and 139 CRC patients, respectively. At the end of the observation period, 58 patients $(37.9 \%)$ were deceased and 37 patients $(27.0 \%)$ experienced a recurrence of the tumour. All deaths were cancer related. The median follow-up for OS and DFS was 4.7 and 4.5 years, respectively.

In the overall study population, the presence of a KRAS mutation was significantly associated with proximal location of the tumours $(P=0.05)$. Age, gender, stage, MSI status and grade of differentiation did not seem to be correlated to the occurrence of a KRAS mutation. Patients with a KRAS mutation showed a shorter OS (HR, 1.70; $P=0.05)$ and DFS (HR, 2.03; $P=0.04)$ compared with patients with wt KRAS in the Kaplan-Meier analysis (Figure 6). The data were even more significant for those with a G12C mutation $(P=0.04$ and $P=0.006$ for OS and DFS, respectively), but the number of patients with a $\mathrm{G} 12 \mathrm{C}$ mutation was extremely small $(n=6)$. Both patients with an MSI tumour $(P=0.05)$ and those with an early-stage tumour had a significantly longer OS, whereas early-stage tumours also had a significantly longer DFS $(P<0.001)$. When entered into a multiple Cox regression analysis adjusting for possible important confounding factors, early stage was still significantly correlated with a longer OS (HR, 1.99; $P<0.001)$ and DFS (HR, 2.35; $P<0.001)$, whereas age only had a significant impact on OS (HR, 1.04; $P<0.001)$. The effect of KRAS mutation on survival could not be confirmed in the multiple Cox regression analysis for the overall population. However, KRAS mutation was still a negative predictor of survival when analysed separately for rectal cancer patients (Table 3 ).

As mentioned earlier, the value of KRAS mutations to define who should benefit from adjuvant chemotherapy and who should not is especially important for stage II CRC. Therefore, a stagedependent survival analysis was performed, which indicated that 

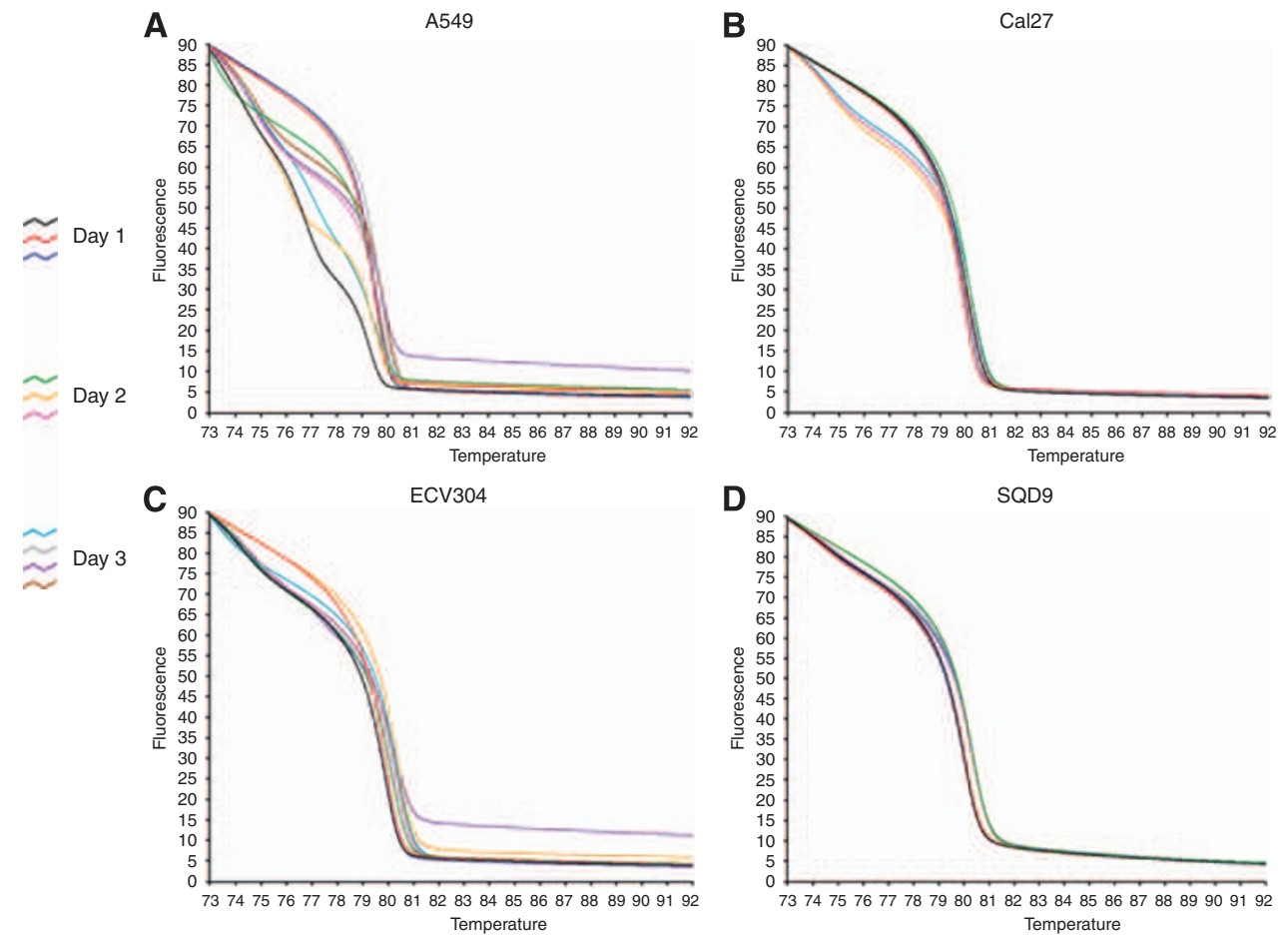

Figure 3 Inter- and intra-variance analysis of four different cell lines (A: A549, B: CAL27, C: ECV304 and D: SQD9) on 3 different days.

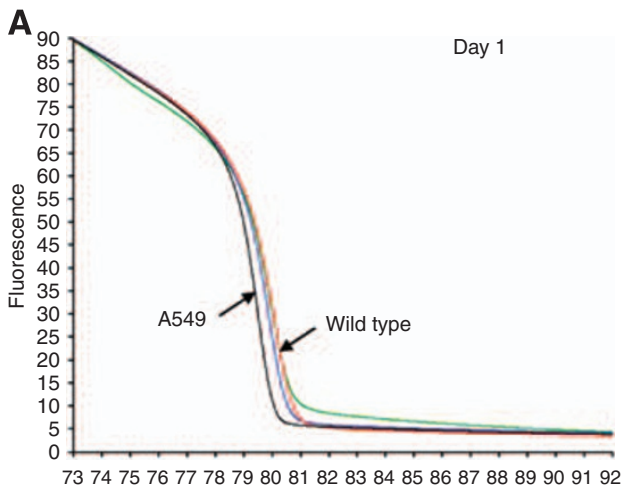
Temperature

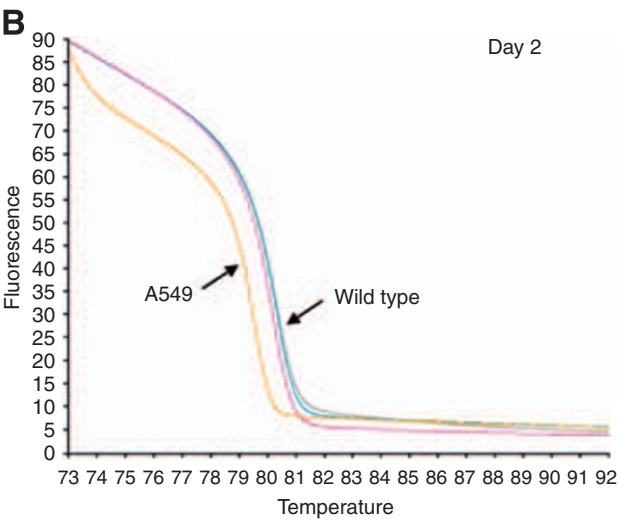

Day 3

Figure 4 Inter- and intra-variation analysis in four different cell lines (three wild type: ECV304, CAL27 and SQD9; one mutant: A549) on 3 consecutive days (A: day I, B: day 2 and $\mathbf{C}$ : day 3). Within each replicate of the same experiment, the mutant cell line (A549) is clearly discriminated from the three wild-type cell lines.

stage II patients with a KRAS mutation had a trend towards a worse DFS (HR, 3.06; $P=0.09$ ), whereas there was no significant association with a worse OS (HR, $1.97 ; P=0.23)$.
Interestingly, when stage II colon and rectal tumours were analysed separately, only the presence of a KRAS mutation in colon cancers was associated with a trend towards a worse DFS 

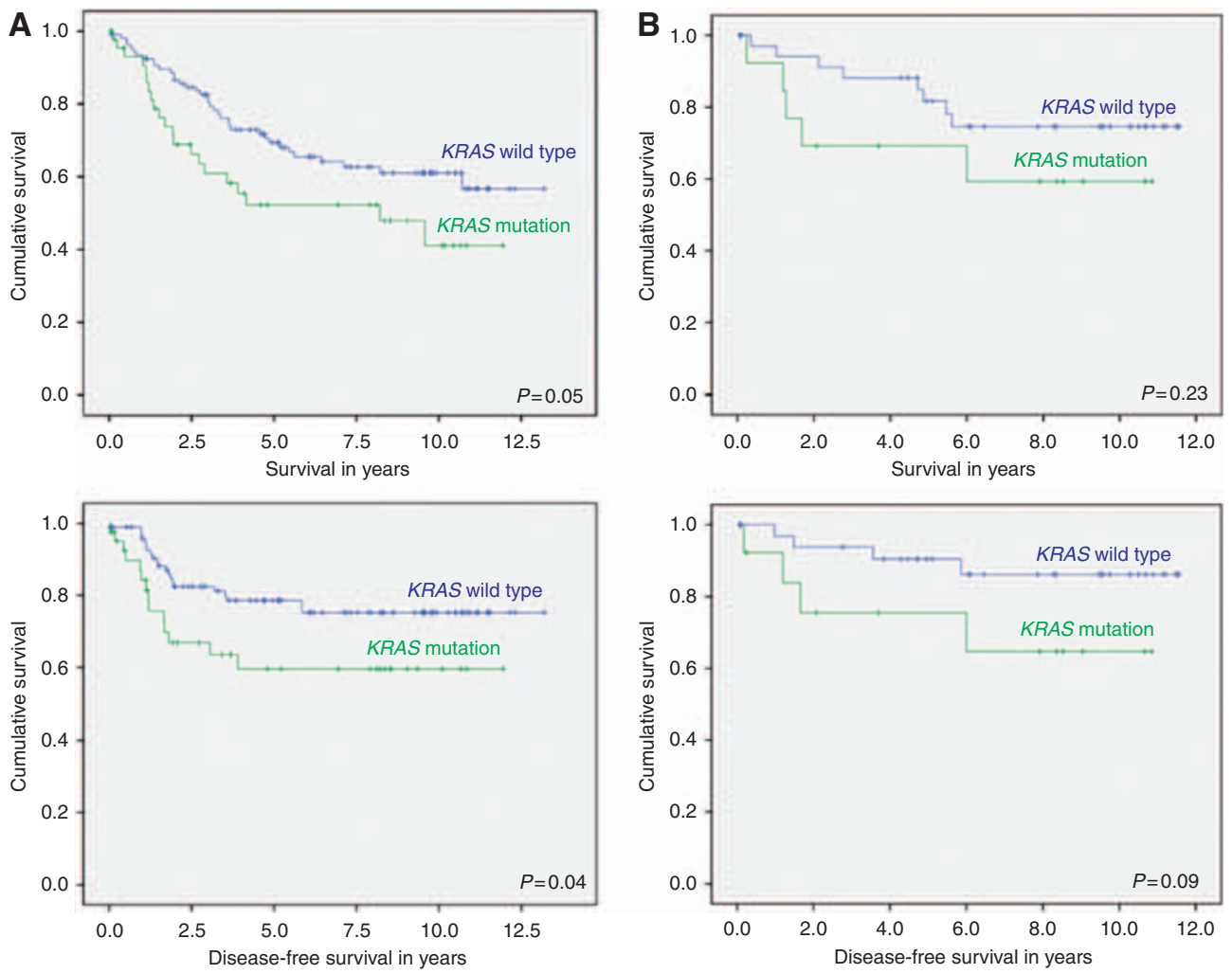

Figure 6 Kaplan-Meier survival analysis for KRAS mutation in CRC of the overall population $(\mathbf{A})$ and of stage II patients in particular (B) for both overall and disease-free survival. Significance was calculated using log-rank statistic.

Table 3 Survival analysis (univariate and Cox regression) for the presence of a KRAS mutation in the overall population and for colon cancer and rectal cancer separately

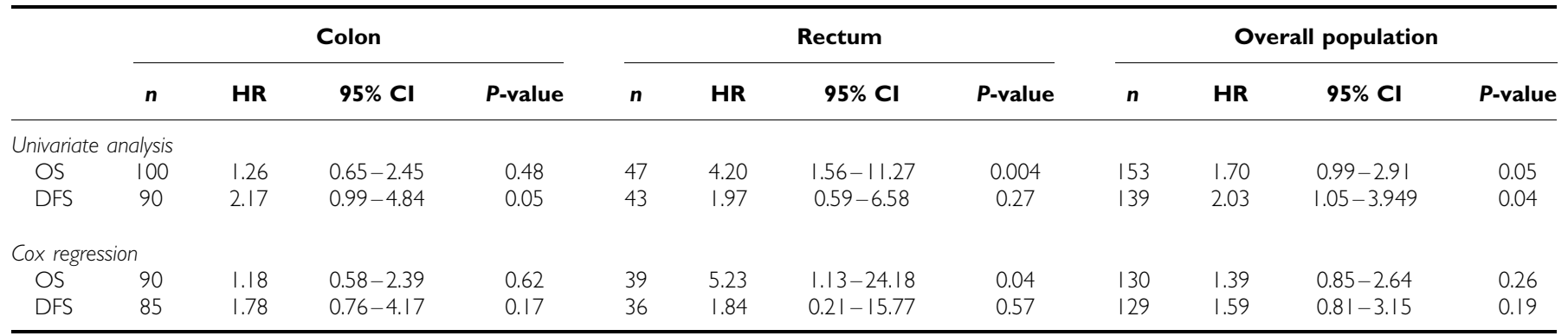

Abbreviations: $95 \% \mathrm{Cl}=95 \%$ confidence interval; DFS = disease-free survival; $\mathrm{HR}=$ hazard ratio; $n=$ number of cases analysed; OS = overall survival. 
(HR, 3.64; $P=0.07$ ), and these results were maintained in the Cox regression analysis $(\mathrm{HR}, 4.163 ; P=0.07)$.

\section{DISCUSSION}

In the era of targeted therapy for cancer, molecular diagnosis of particular genetic markers in tumours enables a more individualised treatment of patients, as was recently shown for KRAS mutation status and response rate to anti-EGFR therapy in CRC (Pichler et al, 2009).

Although it has now been well established that KRAS mutation is a negative predictor for response to anti-EGFR therapy (Allegra et al, 2009; Balko and Black, 2009; Baynes and Gansert, 2009; Javle and Hsueh, 2009; Jimeno et al, 2009; Kohne and Lenz, 2009; Loupakis et al, 2009; Peeters et al, 2009; Saif and Shah, 2009), the prognostic role of KRAS mutations in CRC is still unclear (as reviewed by Anwar et al, 2004; Klump et al, 2004; Locker et al, 2006).

Given the potential impact of KRAS mutation detection for CRC prediction and prognosis, a reliable diagnostic test may affect future therapeutic decision making. In this study, it was demonstrated that HRMA is a reliable and sensitive technology for KRAS mutation detection. First, a cell-line-based model system was used to establish and optimise the KRAS mutation HRMA. A relative short amplicon (114-bp) was used, as it has been stated that amplicon length could influence the sensitivity of genotyping (Krypuy et al, 2006; Pichler et al, 2009). Shorter amplicon lengths have given better resolution of genotypes and increased the sensitivity of mutation detection, even down to $1 \%$ mutated cell DNA (Pichler et al, 2009). Our experiments on reconstituted samples, obtained by serial dilutions of a mutated cancer cell line and normal DNA, indicated the possibility of identifying at least $3 \%$ of mutated alleles in a background of wt DNA, which was the smallest dilution tested. This theoretical sensitivity seems well suited for detecting even a limited percentage of mutated alleles in a heterogeneous sample, as obtained from FFPE CRC tissues (Giuliani et al, 2008). These results are in line with several other studies which found that HRMA could detect $5 \%$ mutated cell DNA in a background of wt DNA (Krypuy et al, 2006; Do et al, 2008; Simi et al, 2008; Pichler et al, 2009). In comparison to sequencing analysis, HRMA seems to be more sensitive in this study, as sequencing analysis had a detection limit of $12.5 \%$ mutated alleles in a background of wt DNA. This is in agreement with the literature, as sequencing requires mutant copies to have a concentration that is at least $20-50 \%$ of any accompanying wt sequences (Ogino et al, 2005; Jimeno et al, 2009; Pichler et al, 2009).

Next, HRMA was validated in a set of DNA obtained from several cell lines (Table 1) with or without a known KRAS mutation. As reported by others (Krypuy et al, 2006; Simi et al, 2008), the heterozygous and homozygous mutations in HCT116, MDA-MB-231 and A549 could be detected with HRMA. In addition, a heterozygous KRAS mutation (G12S) in NCI-H292 was detected by HRMA. These results were confirmed by sequencing analysis. It might be possible that the NCI-H292 cell line acquired a KRAS mutation during prolonged cell culture. Therefore, the KRAS status needs to be examined in an independent NCI-H292 cell line to definitively confirm the presence of the heterozygous KRAS mutation. As mentioned in several studies (Krypuy et al, 2006; Do et al, 2008; Pichler et al, 2009 ), the presence of unspecific PCR products, primer dimers or differing salt or inhibitor concentrations may increase the spread of wt curves. Consequently, it is critical to melt highly specific PCR products. Subsequently, this study showed that inter- and intravariation was present and could hamper the interpretation of the results on HRMA. However, within one experiment, it was still possible to clearly discriminate mutated samples from wt samples.
The KRAS mutations were detected and confirmed by sequencing in 49 of $164(29.9 \%)$ CRC samples. This is in agreement with the literature in which KRAS mutation frequencies range from 30 to $50 \%$ (Jimeno et al, 2009; Peeters et al, 2009). The G/A transitions and G/T transversions were identified as the most frequently found type of KRAS mutation, as described by various studies (Samowitz et al, 2000; Bazan et al, 2005; Poehlmann et al, 2007; Neumann et al, 2009). Codon 12 harboured $23.2 \%$ of the point mutations detected, with the G12D mutation, in which glycine is replaced by aspartic acid, the most prevalent type (40.8\%). These results are confirmed by Simi et al (2008). Although all positive sequencing results were detected by HRMA, some HRMA-positive samples could not be confirmed by sequencing. This might be explained by the fact that adverse effects of formalin fixation on DNA or Taq polymerase errors can cause PCR artefacts during amplification (Srinivasan et al, 2002; Do et al, 2008; Pichler et al, 2009). Unfortunately, fresh frozen tissue was not available for comparison to confirm this hypothesis. Another possibility is that some samples contained levels of mutation below the sensitivity of sequencing detection as a result of low percentage of tumour in the sample or genetic heterogeneity within the tumour (Do et al, 2008). However, in our HRMA, no correlation was found between low DNA concentrations and/or purity and unconfirmed positive samples. In addition, all positive samples were repeated by independent amplification to avoid false-positive results due to errors introduced by Taq polymerase.

It has been known that KRAS point mutations are extremely infrequent in sporadic MSI-H tumours (Ionov et al, 1993; Salahshor et al, 1999; Samowitz et al, 2001; Zhao et al, 2008). However, in several recent reports, it has been shown that the occurrence of mismatch repair $(M M R)$ gene mutations at an early stage might be significant in tumourigenesis through KRAS mutation in MSI-H CRC. It still remains enigmatic why only the mismatch mutL homologue 1 (MLH1) mutation correlates with KRAS mutation, but MLH1 promoter methylation does not, in spite of equally defective MMR leading to a mutator phenotype (Jass, 2002; Zhao et al, 2008; Kumar et al, 2009). In this study, KRAS mutation was found in only one MSI-H sample, which might be explained by the fact that our samples are derived from sporadic CRC in which $M L H 1$ promoter methylation is believed to be the main route of tumourigenesis. The KRAS mutation was associated with proximal location of the tumour. These results are confirmed by others (Elnatan et al, 1996; Samowitz et al, 2000; Andreyev et al, 2001; Oliveira et al, 2007; Ogino et al, 2009b). Kaplan-Meier survival analysis of the entire study population revealed a significantly shorter OS and DFS for CRC patients harbouring a KRAS mutation. In Cox regression, significance of KRAS mutation as a predictor of survival was lost. When colon tumours and rectal tumours were analysed separately, the presence of a KRAS mutation was associated with a worse DFS for colon cancers and a worse OS for rectal tumours in univariate analysis. In Cox regression, only the results for rectal cancer were maintained.

Stage-dependent survival analysis was performed, in particular for stage II, as the value of KRAS mutations to define who should receive adjuvant chemotherapy and who should not is especially important for these patients. In addition, Roth et al (2009) suggested that molecular markers in colon cancer have a stagespecific prognostic value and that different stages might represent different diseases rather than sequential steps in the evolution of a single disease. Kaplan-Meier survival curves revealed a trend towards a worse DFS for stage II patients harbouring a KRAS mutation. When analysed separately for stage II colon cancer and stage II rectal cancer, this trend was only seen in colon cancer patients, and the negative impact was maintained in the Cox regression analysis.

Previous reports have shown conflicting results concerning the relation with prognosis (Laurent-Puig et al, 1992; Andreyev et al, 2001; Losi et al, 2004; Roth et al, 2010). These contradictions are 
partly related to the heterogeneous nature of the relevant studies, but may also be due to the role that stage may have on the effect of genetic factors on prognosis (Cerottini et al, 1998). In addition, recent studies suggest that different KRAS gene mutations have different impacts on outcome (Cerottini et al, 1998; Andreyev et al, 2001). In this study, only G12C substitutions were significantly associated with a worse OS and/or DFS in the overall population, although caution is mandatory because some mutations were only found once. These results are in agreement with Moerkerk et al (1994) who identified G/T and G/C transversions in codon 12 to be associated with advanced disease. Finkelstein et al (1993) established a correlation between G12D mutation and haematogenous metastasis at the time of diagnosis. In the same study, G12V and G13D were found to have no impact on survival. In contrast, prognostic significance for KRAS codon 13 mutations has been reported in CRC (Pajkos et al, 2000; Samowitz et al, 2000; Bazan et al, 2002). The RASCAL II study demonstrated a significant influence on survival of only one mutation, G12V, especially in Dukes C patients (Andreyev et al, 1998, 2001). This was not confirmed in our study, although more G12V than G12C mutations were found. Further analyses are clearly necessary.

In contrast, recent analyses from the CALGB89803 (stage III) and PETACC-3 study (stage II and III) trials did not demonstrate KRAS mutation to be a prognostic marker for colon cancer patients treated with adjuvant 5FU-based chemotherapy (Tejpar et al, 2010). These results are in contrast to those of the RASCAL studies and also to the trend towards a worse DFS in stage II colon cancer patients found in this study. Roth et al (2010) and Ogino et al (2009a) argue that the meta-analyses of Andreyev et al (1998, 2001) substantially suffered from publication bias and possibly resulted in false-positive results because of the number of subset analyses. However, the patients enroled in the randomised trials (GALGB89803 and PETACC-3) may differ from the population at large, as they are selected on the basis of eligibility criteria. Recently, the MRC COIN trial could not find an improvement in the OS or progression-free survival of mCRC patients treated with cetuximab, but they did show that NRAS, KRAS and BRAF were strongly prognostic regardless of cetuximab treatment (Maughan et al, 2010).

The differences between studies might also be related to the retrospective nature of the analyses of single-arm investigations performed in small and often heterogeneous cohorts of patients in which rectal and colon tumours have been examined together. In addition, patients may not have been stratified by stage, gender or

\section{REFERENCES}

Adjei AA (2001) Ras signaling pathway proteins as therapeutic targets. Curr Pharm Des 7: $1581-1594$

Allegra CJ, Jessup JM, Somerfield MR, Hamilton SR, Hammond EH, Hayes DF, McAllister PK, Morton RF, Schilsky RL (2009) American society of clinical oncology provisional clinical opinion: testing for KRAS gene mutations in patients with metastatic colorectal carcinoma to predict response to anti-epidermal growth factor receptor monoclonal antibody therapy. J Clin Oncol 27: 2091-2096

Amado RG, Wolf M, Peeters M, Van CE, Siena S, Freeman DJ, Juan T, Sikorski R, Suggs S, Radinsky R, Patterson SD, Chang DD (2008) Wildtype KRAS is required for panitumumab efficacy in patients with metastatic colorectal cancer. J Clin Oncol 26: 1626-1634

Andreyev HJ, Norman AR, Cunningham D, Oates J, Dix BR, Iacopetta BJ, Young J, Walsh T, Ward R, Hawkins N, Beranek M, Jandik P, Benamouzig R, Jullian E, Laurent-Puig P, Olschwang S, Muller O, Hoffmann I, Rabes HM, Zietz C, Troungos C, Valavanis C, Yuen ST, Ho JW, Croke CT, O'Donoghue DP, Giaretti W, Rapallo A, Russo A, Bazan V, Tanaka M, Omura K, Azuma T, Ohkusa T, Fujimori T, Ono Y, Pauly M, Faber C, Glaesener R, de Goeij AF, Arends JW, Andersen SN, Lovig T, Breivik J, Gaudernack G, Clausen OP, De Angelis PD, Meling GI, Rognum TO, Smith R, Goh HS, Font A, Rosell R, Sun XF, Zhang H, age. Thus, many have been statistically underpowered to provide meaningful results (Tejpar et al, 2010). However, in this study, although retrospective in nature, colon and rectal tumours were analysed separately and patients were stratified according to stage. In addition, a lack of standardisation of methodologies for marker assessment has resulted in data that are not comparable, and not all mutations within a given gene are always screened for, possibly leading to underestimation of the role of KRAS mutations (Tejpar et al, 2010). Larger prospective studies are required to provide a decisive answer, if possible.

The predictive value of KRAS, that is, whether or not patients will respond to anti-EGFR therapy, could not be analysed in this retrospective study, as anti-EGFR mAbs were not available for treatment of these patients at the time. In addition, only $13.7 \%$ of the study population had distant metastases, the setting for which treatment with anti-EGFR therapy has been approved (Allegra et al, 2009; Heinemann et al, 2009; Jimeno et al, 2009). However, of the mCRC patients in our study population, $50 \%$ had a KRAS mutation, which would render anti-EGFR therapy ineffective. This underlines the importance of KRAS mutation analysis.

In conclusion, HRMA was found to be a fast, efficient and reproducible screening method for KRAS mutation detection, using which also DNA from FFPE tissues can be tested. However, further validation studies are needed before this technique can be used in the clinical setting. The KRAS mutation in our retrospective study came forward as a negative predictive factor for OS in patients with rectal cancer and for DFS in stage II colon cancer patients (trend). Our data support the idea that evidence is accumulating that poor outcome could be linked to specific mutations and that specific gene mutations might have an impact on patient selection for adjuvant treatment.

\section{ACKNOWLEDGEMENTS}

We acknowledge support of the Special Research Fund of the University of Antwerp, Belgium (granted to MB). In addition, we would like to thank the Translational Cancer Research Group (Dr Dirix and Dr Vermeulen) for providing tissue samples.

\section{Conflict of interest}

The authors declare no conflict of interest.
Benhattar J, Losi L, Lee JQ, Wang ST, Clarke PA, Bell S, Quirke P, Bubb VJ, Piris J, Cruickshank NR, Morton D, Fox JC, Al-Mulla F, Lees N, Hall CN, Snary D, Wilkinson K, Dillon D, Costa J, Pricolo VE, Finkelstein SD, Thebo JS, Senagore AJ, Halter SA, Wadler S, Malik S, Krtolica K, Urosevic N (2001) Kirsten ras mutations in patients with colorectal cancer: the 'RASCAL II' study. Br J Cancer 85: 692-696

Andreyev HJ, Norman AR, Cunningham D, Oates JR, Clarke PA (1998) Kirsten ras mutations in patients with colorectal cancer: the multicenter 'RASCAL' study. J Natl Cancer Inst 90: 675-684

Anwar S, Frayling I, Scott N, Carlson G (2004) Systematic review of genetic influences on the prognosis of colorectal cancer. Br J Surg 91: 1275-1291

Balko JM, Black EP (2009) A gene expression predictor of response to EGFR-targeted therapy stratifies progression-free survival to cetuximab in KRAS wild-type metastatic colorectal cancer. BMC Cancer 9: 145

Baynes RD, Gansert J (2009) KRAS mutational status as a predictor of epidermal growth factor receptor inhibitor efficacy in colorectal cancer. Am J Ther 16: $554-561$

Bazan V, Agnese V, Corsale S, Calo V, Valerio MR, Latteri MA, Vieni S, Grassi N, Cicero G, Dardanoni G, Tomasino RM, Colucci G, Gebbia N, Russo A (2005) Specific TP53 and/or Ki-ras mutations as independent predictors of clinical outcome in sporadic colorectal 
adenocarcinomas: results of a 5-year Gruppo Oncologico dell'Italia Meridionale (GOIM) prospective study. Ann Oncol 16(Suppl 4): iv50 - iv55 Bazan V, Migliavacca M, Zanna I, Tubiolo C, Grassi N, Latteri MA, La FM, Albanese I, Dardanoni G, Salerno S, Tomasino RM, Labianca R, Gebbia N, Russo A (2002) Specific codon 13 K-ras mutations are predictive of clinical outcome in colorectal cancer patients, whereas codon $12 \mathrm{~K}$-ras mutations are associated with mucinous histotype. Ann Oncol 13: $1438-1446$

Cerottini JP, Caplin S, Saraga E, Givel JC, Benhattar J (1998) The type of K-ras mutation determines prognosis in colorectal cancer. Am J Surg 175: $198-202$

Conlin A, Smith G, Carey F, Wolf C, Steele R (2005) The prognostic significance of K-ras, p53, and APC mutations in colorectal carcinoma. Gut 54: $1283-1286$

Deschoolmeester V, Baay M, Wuyts W, Van ME, Pelckmans P, Lardon F, Vermorken JB (2006) Comparison of three commonly used PCR-based techniques to analyze MSI status in sporadic colorectal cancer. J Clin Lab Anal 20: $52-61$

Deschoolmeester V, Van Damme N, Baay M, Claes K, Van ME, Baert FJ, Wuyts W, Cabooter M, Weyler J, Vermeulen P, Lardon F, Vermorken JB, Peeters M (2008) Microsatellite instability in sporadic colon carcinomas has no independent prognostic value in a Belgian study population. Eur J Cancer 44: 2288-2295

Do H, Krypuy M, Mitchell PL, Fox SB, Dobrovic A (2008) High resolution melting analysis for rapid and sensitive EGFR and KRAS mutation detection in formalin fixed paraffin embedded biopsies. BMC Cancer 8: 142

Elnatan J, Goh HS, Smith DR (1996) C-KI-RAS activation and the biological behaviour of proximal and distal colonic adenocarcinomas. Eur J Cancer 32A: $491-497$

Finkelstein SD, Sayegh R, Bakker A, Swalsky P (1993) Determination of tumor aggressiveness in colorectal cancer by K-ras-2 analysis. Arch Surg 128: $526-531$

Giuliani L, Ronci C, Bonifacio D, Di BL, Favalli C, Perno CF, Syrjanen K, Ciotti M (2008) Detection of oncogenic DNA viruses in colorectal cancer. Anticancer Res 28: 1405-1410

Graziano F, Cascinu S (2003) Prognostic molecular markers for planning adjuvant chemotherapy trials in Dukes' B colorectal cancer patients: how much evidence is enough? Ann Oncol 14: 1026-1038

Heinemann V, Stintzing S, Kirchner T, Boeck S, Jung A. (2009) Clinical relevance of EGFR- and KRAS-status in colorectal cancer patients treated with monoclonal antibodies directed against the EGFR. Cancer Treat Rev 35: $262-271$

Ionov Y, Peinado M, Malkhosyan S, Shibata D, Perucho M (1993) Ubiquitous somatic mutations in simple repeated sequences reveal a new mechanism for colonic carcinogenesis. Nature 363: 558-561

Jass JR (2002) Pathogenesis of colorectal cancer. Surg Clin N Am 82: $891-904$

Javle M, Hsueh CT (2009) Updates in Gastrointestinal Oncology-insights from the 2008 44th annual meeting of the American Society of Clinical Oncology. J Hematol Oncol 2: 9

Jimeno A, Messersmith WA, Hirsch FR, Franklin WA, Eckhardt SG (2009) KRAS mutations and sensitivity to epidermal growth factor receptor inhibitors in colorectal cancer: practical application of patient selection. J Clin Oncol 27: 1130-1136

Klump B, Nehls O, Okech T, Hsieh CJ, Gaco V, Gittinger FS, Sarbia M, Borchard F, Greschniok A, Gruenagel HH, Porschen R, Gregor M (2004) Molecular lesions in colorectal cancer: impact on prognosis? Original data and review of the literature. Int J Colorectal Dis 19: $23-42$

Kohne CH, Lenz HJ (2009) Chemotherapy with targeted agents for the treatment of metastatic colorectal cancer. Oncologist 14: $478-488$

Kramer D, Thunnissen FB, Gallegos-Ruiz MI, Smit EF, Postmus PE, Meijer CJ, Snijders PJ, Heideman DA (2009) A fast, sensitive and accurate high resolution melting (HRM) technology-based assay to screen for common K-ras mutations. Cell Oncol 31: 161-167

Krypuy M, Newnham GM, Thomas DM, Conron M, Dobrovic A (2006) High resolution melting analysis for the rapid and sensitive detection of mutations in clinical samples: KRAS codon 12 and 13 mutations in nonsmall cell lung cancer. BMC Cancer 6: 295

Kumar K, Brim H, Giardiello F, Smoot DT, Nouraie M, Lee EL, Ashktorab H (2009) Distinct BRAF (V600E) and KRAS mutations in high microsatellite instability sporadic colorectal cancer in African Americans. Clin Cancer Res 15: 1155-1161
Laurent-Puig P, Olschwang S, Delattre O, Remvikos Y, Asselain B, Melot T, Validire P, Muleris M, Girodet J, Salmon RJ (1992) Survival and acquired genetic alterations in colorectal cancer. Gastroenterology 102: $1136-1141$

Lievre A, Bachet JB, Le CD, Boige V, Landi B, Emile JF, Cote JF, Tomasic G, Penna C, Ducreux M, Rougier P, Penault-Llorca F, Laurent-Puig P (2006) KRAS mutation status is predictive of response to cetuximab therapy in colorectal cancer. Cancer Res 66: 3992-3995

Locker G, Hamilton S, Harris J, Jessup J, Kemeny N, Macdonald J, Somerfield M, Hayes D, Bast R (2006) ASCO 2006 update of recommendations for the use of tumor markers in gastrointestinal cancer. J Clin Oncol 24: 5313-5327

Losi L, Luppi G, Benhattar J (2004) Assessment of K-ras, Smad4 and p53 gene alterations in colorectal metastases and their role in the metastatic process. Oncol Rep 12: $1221-1225$

Loupakis F, Pollina L, Stasi I, Ruzzo A, Scartozzi M, Santini D, Masi G, Graziano F, Cremolini C, Rulli E, Canestrari E, Funel N, Schiavon G, Petrini I, Magnani M, Tonini G, Campani D, Floriani I, Cascinu S, Falcone A (2009) PTEN expression and KRAS mutations on primary tumors and metastases in the prediction of benefit from cetuximab plus irinotecan for patients with metastatic colorectal cancer. J Clin Oncol 27: $2622-2629$

Maughan TS, Adams R, Smith CG, Seymour MT, Wilson AM, Meade AM, Fisher D, Madi A, Cheadle J, Kaplan RS (2010) Identification of potentially responsive subsets when cetuximab is added to oxaliplatinfluoropyrimidine chemotherapy (CT) in first-line advanced colorectal cancer (aCRC): mature results of the MRC COIN trial. J Clin Oncol (Meeting abstract) 28(Suppl): 3502

Moerkerk P, Arends JW, van DM, de BA, de GA, ten KJ (1994) Type and number of Ki-ras point mutations relate to stage of human colorectal cancer. Cancer Res 54: 3376-3378

Neumann J, Zeindl-Eberhart E, Kirchner T, Jung A (2009) Frequency and type of KRAS mutations in routine diagnostic analysis of metastatic colorectal cancer. Pathol Res Pract 205: 858-862

Ogino S, Kawasaki T, Brahmandam M, Yan L, Cantor M, Namgyal C, MinoKenudson M, Lauwers GY, Loda M, Fuchs CS (2005) Sensitive sequencing method for KRAS mutation detection by Pyrosequencing. J Mol Diagn 7: 413-421

Ogino S, Meyerhardt JA, Irahara N, Niedzwiecki D, Hollis D, Saltz LB, Mayer RJ, Schaefer P, Whittom R, Hantel A, Benson III AB, Goldberg RM, Bertagnolli MM, Fuchs CS (2009a) KRAS mutation in III stage colon cancer and clinical outcome following intergroup trial CALGB 89803. Clin Cancer Res 15: 7322-7329

Ogino S, Nosho K, Kirkner GJ, Kawasaki T, Meyerhardt JA, Loda M, Giovannucci EL, Fuchs CS (2009b) CpG island methylator phenotype, microsatellite instability, BRAF mutation and clinical outcome in colon cancer. Gut 58: $90-96$

Oliveira C, Velho S, Moutinho C, Ferreira A, Preto A, Domingo E, Capelinha A, Duval A, Hamelin R, Machado J, Schwartz Jr S, Carneiro F, Seruca R (2007) KRAS and BRAF oncogenic mutations in MSS colorectal carcinoma progression. Oncogene 26: $158-163$

Pajkos G, Kiss I, Sandor J, Ember I, Kishazi P (2000) The prognostic value of the presence of mutations at the codons 12, 13, 61 of K-ras oncogene in colorectal cancer. Anticancer Res 20: 1695-1701

Peeters M, Price T, Van Laethem JL (2009) Anti-epidermal growth factor receptor monotherapy in the treatment of metastatic colorectal cancer: where are we today? Oncologist 14: 29-39

Pichler M, Balic M, Stadelmeyer E, Ausch C, Wild M, Guelly C, Bauernhofer T, Samonigg H, Hoefler G, Dandachi N (2009) Evaluation of high-resolution melting analysis as a diagnostic tool to detect the BRAF V600E mutation in colorectal tumors. J Mol Diagn 11: 140-147

Poehlmann A, Kuester D, Meyer F, Lippert H, Roessner A, Schneider-Stock R (2007) K-ras mutation detection in colorectal cancer using the Pyrosequencing technique. Pathol Res Pract 203: 489-497

Roth A, Tejpar S, Yan P, Fiocca R, Dietrich D, Delorenzi M, Labianca R, Cunningham D, Van Cutsem E, Bosman F (2009) Stage-specific prognostic value of molecular markers in colon cancer: results of the translational study on the PETACC 3-EORTC 40993-SAKK 60-00 trial. $J$ Clin Oncol (Meeting abstract) 27: 4002

Roth AD, Tejpar S, Delorenzi M, Yan P, Fiocca R, Klingbiel D, Dietrich D, Biesmans B, Bodoky G, Barone C, Aranda E, Nordlinger B, Cisar L, Labianca R, Cunningham D, Van CE, Bosman F (2010) Prognostic role of KRAS and BRAF in stage II and III resected colon cancer: results of the translational study on the PETACC-3, EORTC 40993, SAKK 60-00 trial. J Clin Oncol 28: $466-474$ 
Saif MW, Shah M (2009) K-ras mutations in colorectal cancer: a practice changing discovery. Clin Adv Hematol Oncol 7: 45-53, 64

Salahshor S, Kressner U, Fischer H, Lindmark G, Glimelius B, Pahlman L, Lindblom A (1999) Microsatellite instability in sporadic colorectal cancer is not an independent prognostic factor. Br J Cancer 81: 190-193

Samowitz WS, Curtin K, Coleman LW, Slattery ML (2001) Microsatellite instability in sporadic colon cancer is associated with an improved prognosis at the population level. Cancer Epidemiol Biomarkers Prev 10: 917-923

Samowitz WS, Curtin K, Schaffer D, Robertson M, Leppert M, Slattery ML (2000) Relationship of Ki-ras mutations in colon cancers to tumor location, stage, and survival: a population-based study. Cancer Epidemiol Biomarkers Prev 9: 1193-1197

Simi L, Pratesi N, Vignoli M, Sestini R, Cianchi F, Valanzano R, Nobili S, Mini E, Pazzagli M, Orlando C (2008) High-resolution melting analysis for rapid detection of KRAS, BRAF, and PIK3CA gene mutations in colorectal cancer. Am J Clin Pathol 130: 247-253

Srinivasan M, Sedmak D, Jewell S (2002) Effect of fixatives and tissue processing on the content and integrity of nucleic acids. Am J Pathol 161: $1961-1971$

Tejpar S, Bertagnolli M, Bosman F, Lenz HJ, Garraway L, Waldman F, Warren R, Bild A, Collins-Brennan D, Hahn H, Harkin DP, Kennedy R, Ilyas M, Morreau H, Proutski V, Swanton C, Tomlinson I, Delorenzi M, Fiocca R, Van CE, Roth A (2010) Prognostic and predictive biomarkers in resected colon cancer: current status and future perspectives for integrating genomics into biomarker discovery. Oncologist 15: 390-404

Zhao Y, Miyashita K, Ando T, Kakeji Y, Yamanaka T, Taguchi K, Ushijima T, Oda S, Maehara Y (2008) Exclusive KRAS mutation in microsatelliteunstable human colorectal carcinomas with sequence alterations in the DNA mismatch repair gene, MLH1. Gene 423: 188-193 